\title{
Research on the Protection of the Architectural Culture of the Traditional Villages of the Qiang Nationality-Taking Taoping Qiang Village as an Example
}

\author{
Biyun Li \\ Southwest Minzu University, Chengdu, China \\ Email: 903320396@qq.com
}

How to cite this paper: Li, B.Y. (2020) Research on the Protection of the Architectural Culture of the Traditional Villages of the Qiang Nationality-Taking Taoping Qiang Village as an Example. Open Access Library Journal, 7: e6876. https://doi.org/10.4236/oalib.1106876

Received: September 30, 2020

Accepted: October 27, 2020

Published: October 30, 2020

Copyright $\odot 2020$ by author(s) and Open Access Library Inc.

This work is licensed under the Creative Commons Attribution International License (CC BY 4.0).

http://creativecommons.org/licenses/by/4.0/

(c) (i) Open Access

\begin{abstract}
Architectural culture is the sum of architectural material wealth and architectural spiritual wealth created in the course of human social and historical practice. Building is the carrier of architectural culture. It is loaded with information about the mutual movement of human beings, society, nature and architecture. The synthesis of these information is architectural culture. Architectural culture is an important part of human culture. Research on its protection status can find the memory of history and culture. The architecture of the Qiang ethnic group embodies the unique culture of our nation, and Taoping Qiang Village is a typical example. Taoping Qiang Village is located in the Tibetan-Yi Corridor. It is a typical Sichuan Diaolou dwelling. The Tibetans, Han and Qiang nationalities frequently interact in this area. Eco-city research on Taoping Qiang Village is related to the well-being of the people in traditional villages in ethnic areas. Our study of the protection status of its architectural culture also provides a new example for the construction of traditional village protection. This article first elaborates on the concept of architectural culture and its classification, and then introduces the related architectural culture of Taoping Qiang Village and its protection status and problems in the protection, and finally puts forward some corresponding suggestions for the existing problems.
\end{abstract}

\section{Subject Areas}

Architecture, Culture

\section{Keywords}

Qiang Nationality, Taoping Qiang Village, Architecture 


\section{Architectural Culture}

\subsection{The Concept of Architectural Culture}

Architectural culture is an integral part of the overall culture of society. Buildings are the carrier of architectural culture. It is loaded with information about the mutual movement of human beings, society, nature and architecture. The synthesis of these information is architectural culture.

Architectural culture itself is a branch of generalized culture. At the same time, architecture is also a container for other cultures and a comprehensive reflection of other cultures. The cultural diversity, regionality, time and hierarchy will inevitably have a profound impact on the development of architecture [1]. Architectural culture is not only the embodiment of the overall social culture in the construction activities, but also the feedback of the construction activities to the social culture. The two promote each other and occur simultaneously.

\subsection{Classification of Architectural Culture and Qiang Architecture}

\subsubsection{Classification of Architectural Culture}

According to the author's summary of architectural culture materials, architectural culture is mainly divided into the following aspects (Table 1).

\subsubsection{Overview of Qiang Architecture}

Qiang Diaolou is one of the most characteristic buildings of the Qiang Nationality, and the "Qiang Diaolou Construction Techniques" has been included in the third batch of the expanded list of national intangible cultural heritage [2]. The Qiang people have created a splendid culture in the upper reaches of the Minjiang River in Sichuan Province with their diligent, kind-hearted national genes and ancient and simple production and lifestyle, living in the plateau with harsh natural conditions and harsh climate with an uncontested view of happiness.

\subsubsection{Architecture Types of Qiang Nationality}

According to Professor Zhang Guoxiong's opinion, Qiang's watchtowers can be divided into three types: "One type is a watchtower specially used for observation and defensive operations, generally up to 10 meters high and 10 stories high; the other is mainly for residential use. Most of the houses are three-storey; one type is a combination of residence and defense. The front is a blockhouse,

Table 1. Classification of architectural culture.

\begin{tabular}{cc}
\hline Single building \\
Architectural culture & Buildings \\
Attachment & Structure \\
Architectural modeling & Building materials use
\end{tabular}


and the back is a blockhouse, which is connected as a whole." If it is further subdivided, Qiang blockhouses can be divided into four categories according to their functions: one is as a chieftain Guanzhai Diaolou, a symbol of power status and defense, is a four-cornered Diaolou. The second is a military defensive block built inside and outside the village and the main traffic pass, with four-cornered, five-cornered, hexagonal, and octagonal blockhouses; the third is a warning block built on the mountain with a wide view area for sounding warnings and setting off beacon smoke [3]. It is called "Bao Huo Diao", and its shape is a four-cornered Diaolou; the fourth is a Diaolou built in the village as a defense against looting for homeowners to store valuables. The Diaolou is built with four corners, five corners and octagonal. More than 20 meters away, this type of watchtower was used to store property and food in peaceful times. During the war, Qiang fighters entered the watchtower to prepare for battle, while the people took refuge in it. We call one or two of these four types "war bunkers", which are dedicated to war and can be stationed in troops and guard the gates; the third type is called "village bunkers" or "zhai bunkers", and it is mostly a village. The common people of the People's Republic of China jointly funded the construction, generally built in the middle or around the village; the fourth category is the "House Diaolou", which is the most functional and closest to the people's daily life [4]. It is the most spatially compatible state between Qiang folk house and Diaolou.

\section{The Architectural Culture of Taoping Qiang Village}

\subsection{Overview of Taoping Qiang Village}

Taoping Qiangzhai is located beside National Highway 317 of the Zagunao River, a tributary of the Minjiang River, on the alluvial fan-shaped platform of Zengtougou, a tributary of the Zagunao River, with Jiashan on the south and Dongshan and Xishan on the north. Taoping Qiang Village is about 160 kilometers away from Chengdu and 20 kilometers away from Wenchuan County. The specific location of the village is $103^{\circ} 26^{\prime}$ east longitude, $31^{\circ} 33^{\prime}$ north latitude, and 1500 meters above sea level. Taoping Village has an area of 729 acres of arable land, a permanent population of 946, and the main ethnic group is Qiang [5]. The population of Taoping Qiang Village is about 400 people, most of them are located on the north side of Zagunao River. The north side is divided into two parts. Taoping Qiang Village is in the east and the terrain is higher. There are a total of 113 houses in the village. It has been developed as a tourist attraction. The terrain of Taoping Qiang Village is decreasing from north to south.

\subsection{Taoping Qiang Village Architectural Culture}

The architecture of the Qiang nationality is one of the core contents of the Qiang Cultural and Ecological Protection Experimental Area. The architecture of the Qiang Village in Taoping is a representative of the architecture of the Qiang Nationality [6]. It can be said that the architecture of the Qiang Village is a crucial 
factor for the Taoping Qiang Village to be assessed as a national traditional village. The tourism development that began in the late 1990s is of great significance to the Taoping Qiang Village. The village has changed from obscurity to a large number of tourists, and the villagers have gradually changed from living on the land to now engage in tourism and reception, and the Qiang connecting the environment and local residents. With the development of history, the significance of village architecture has also undergone a huge change. It is such a change that makes Taoping Qiang Village gradually become what we are familiar with today.

\subsubsection{Diaolou}

The most iconic building in Taoping's Qiang Village is the Diaolou. There are three Diaolou in Qiang Village, namely Xiaoqiong Qiang's Diaolou, Chen's Diaolou, and Yu's Diaolou (Figure 1). The three towers are arranged from south to north and are surrounded by surrounding buildings. Because of their unique shape and higher than the surrounding buildings, they are very conspicuous from a distance. The Diaolou and the surrounding dwellings are known as the "Mysterious Oriental Castle". Such a title is a sincere admiration for the architecture of Taoping Qiang Village. Taoping Qiangzhai Diaoqu was listed in the sixth batch of national key cultural relics protection units by the State Administration of Cultural Heritage in May 2006, and was also included in the fifth batch of national key cultural relics protection units Zhibo Diaolou. Not only that, Taoping Qiang Village was included in the "China World Cultural Heritage Preliminary List” in 2007. In 2012, Taoping Qiang Village was named the first batch of national traditional villages. National key cultural relics protection units, China's World Cultural Heritage Reserve List, and national-level traditional villages [7]. These various titles mainly assessed by the government seem to be halo after halo. This is an affirmation of Taoping Qiang Village. We are under halo The Taoping Qiang Village will undoubtedly shine exceptionally.

\subsubsection{Residential Building}

Taoping Qiang people's residential buildings use "stone" as the main material and "barrier" as the technical means. The building is built on the hillside, and is

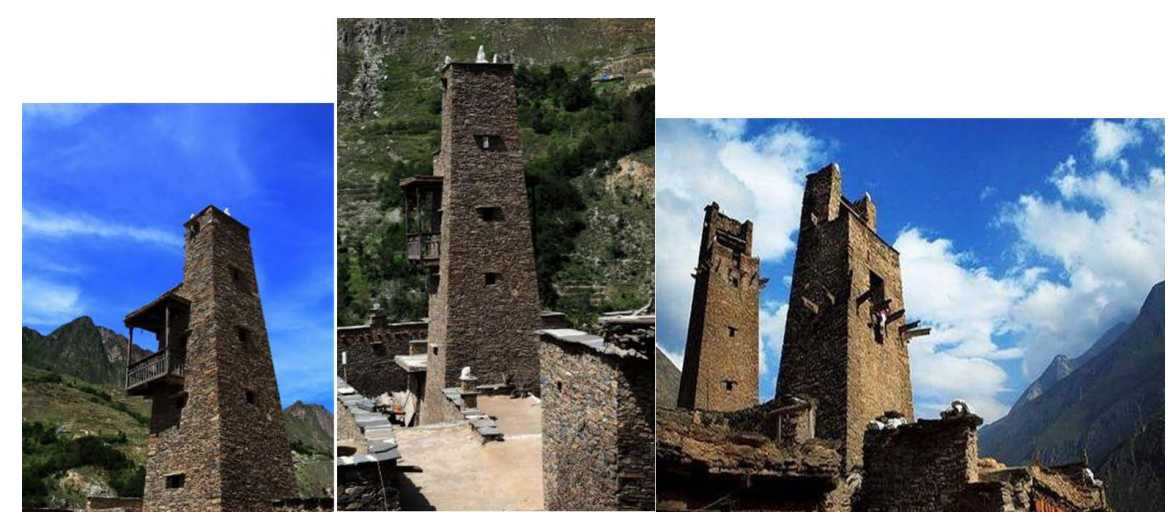

Figure 1. Photos of Xiaoqiong Qiang's Diaolou, Chen's Diaolou, and Yu's Diaolou. 
composed of the horizontal residential space structure and the vertical multi-story tower space, as well as the ancient Qiang architectural theory that one column defines the world. It constitutes the world mode of Qiang people's perception.

First of all, the Qiang people are original in the choice of building materials. The residential buildings of the Qiang people are called "Kile" in Qiang language, which is a family house, and Diaolou is called "Luoze" in Qiang language, which is a stone building that symbolizes the highest spirit of the Qiang people. They used local "stone, mud, and wood" as materials. For residential buildings, a square ditch with a depth of about 1 meter is generally first dug into the ground, and then a layer of stones is used to build a foundation. Yellow mud and lime flakes form a wall. Taoping Qiangzhai dwellings often use stone chips and loess to rammed flat-roof houses, and the layout of roof facilities will have a certain impact on people's psychology. People can feel the charm of space only in an environment with moderate light brightness, harmonious colors and reasonable spatial scale [8]. The interior color is generally based on neutral light colors, which is conducive to set off the furniture. This is also related to the residents' hobbies and personality. For example, a male singer and a female writer may have completely different interior layouts in their houses: the singer's living room is spacious, covered with beige plush carpet, which looks soft and comfortable, and the sofa is also surrounded by fluff, with few ornaments, and allows children to be free. Play and roll. The writer's living room is elegantly furnished, with many artworks and murals on display. She hopes to return home to appreciate herself, as if she is living in her own illusion, pursuing a harmonious and pleasant atmosphere. It can be seen that the space design and design style of the house are related to the temperament and occupation of the owner [9].

The bedroom adopts soft and light colors, which can improve the brightness of the space and have a sense of spatial expansion. The furniture should be light-colored, and the color is simple and elegant and easy to coordinate with the indoor environment. The color of the furnishings belongs to the "emphasis color" in the entire indoor environment, which enriches the indoor color and creates a happy and lively atmosphere. Through the study of people's psychological feelings about the environment, their personal space, and people's psychological feelings about the living environment, the design can be considered more comprehensively according to the impact of the environment on people, so as to design a beautiful, convenient and reasonable layout, A warm atmosphere and full of fun living environment.

\section{Problems in the Protection of Taoping Qiang Village's Architectural Culture}

\subsection{Residents Have Weak Awareness of Protection}

With the continuous deepening of tourism development, the huge visiting value of Taoping Qiangzhai architecture has attracted more and more tourists, and the function of the building has gradually shifted to visiting and sightseeing. Under 
this situation, Taoping Qiang Village was transformed into a tourist attraction. In order to better serve tourists, local villagers renovated the buildings in Qiang Village. While renovating the Qiangzhai buildings, the villagers also destroyed the original features of the buildings. Looking at Taoping's Qiang Village from a high place, you will find that many houses' roofs are made of cement for waterproofing convenience, while traditional building roofs use local yellow mud. Many residents used modern building materials in the process of rebuilding their houses, which led to the conversion of the original stone-wood structure into brick-concrete structure. The modern decoration style introduced in the decoration style is very different from the original style of Laozhai. The decline of local residents' protection of buildings also directly led to tourists' perception of Taoping Qiangzhai buildings.

\subsection{The Disappearance of Traditional Culture about Architecture}

The change of architectural function and the reconstruction of meaning in Taoping Qiang Village led to the disappearance of local traditional culture based on architecture. Taoping Qiang Village, as a traditional village of Qiang nationality, is facing the withering of local traditional culture of Qiang nationality, and the disappearance of Qiang language place names is one of the representatives. There were a large number of Qiang language place names used by villagers in daily life in Taoping Laozhai. These place names were generated to identify the specific location of the residents in the village, and their meanings were especially expressed by something with distinctive features. During the visit, it was discovered that although many Qiang language place names are still preserved, they are not known to people. With the establishment of the Taoping Qiangzhai New District, most of the villagers moved and evacuated. Qiang language place names gradually disappeared in people's daily conversations, and the Qiang culture behind it also gradually disappeared.

\subsection{Low Utilization Rate of Qiangzhai Dwellings}

During the post-disaster reconstruction process, the government built the Taoping Qiangzhai New District. This specially established tourist service area for the original intention of protecting the Taoping Qiang Village and Laozhai Village diverts tourists to a certain extent, reduces the time for tourists to stay in the Laozhai Village, and thus protects the buildings of the Laozhai Village to a certain extent. However, Taoping Qiang Village, a traditional village, is facing a hollow population. The vast majority of villagers bought houses in the new district and moved into it. The function of buildings in Laozhai for people to live in has gradually disappeared, and the sacrifices and other activities performed by the people in the buildings where they lived are also transferred to the new residence. Except for a few tourist attractions in Laozhai, most of the remaining houses are locked and unoccupied. The houses are left idle. 


\section{Some Suggestions on the Protection of Taoping Qiang Village Architectural Culture}

\subsection{Guide Villagers to Spontaneously Participate in Protection}

The subjective initiative of local residents should be brought into play. After using new media and offline channels to learn about the relevant knowledge of traditional villages, it will be feasible for villagers to participate in the protection spontaneously. The protection of traditional villages can be carried out with the help of platforms, which can be built with the joint efforts of third-party public welfare funds and villagers. It can be transformed from an idle building in a traditional village, and the platform is also a small museum. In this way, it can not only be a platform for external display of village culture, but also a platform for villagers to spontaneously participate in the protection of traditional villages. Villagers and related scholars can use the platform to carry out interactive communication, so that more people can experience the cultural connotation of traditional architecture. The museum is also a data center, which can be used to collect and store information about buildings. Villagers can exchange ideas on how to protect traditional villages. The construction of the platform is by no means just for simply storing relevant information. The platform is mainly composed of villagers participating in the joint construction of the platform. It should also serve the local villagers. It can even become a collective think tank for the villagers to participate in the committee's formulation of ideas.

\subsection{Re-Creation of Traditional Historical and Cultural Resources in Ethnic Areas}

It is an indisputable fact that the way of inheriting culture in traditional villages in ethnic areas changes with the development of the village's tourism economy. The re-creation of the historical and cultural resources of traditional villages in ethnic areas can re-excavate the rich connotations of traditional villages. At present, the new type of folk dance has a certain substitution and inheritance to the traditional ethnic architectural culture. As far as the current situation is concerned, the new way of cultural inheritance in traditional villages in ethnic areas is linked with the previous way of national cultural inheritance, and the new method of cultural inheritance is used to increase the charm of traditional buildings. For example, in Taoping Qiang Village, the old buildings of Taoping Qiang Village can be appropriately transformed into an event space that integrates dance rehearsals and villagers' daily cultural and entertainment activities, and staged real-life dance performances based on the architecture. Tourists can also participate in the interaction in the architectural space while feeling the charm of traditional dance and architecture. With regard to the core elements of traditional villages in ethnic areas, the author believes that they can be used as creative blueprints to design and produce cultural and creative products. These cultural and creative products include cross-stitching and scaled buildings with 
the appearance of landmark buildings in traditional villages in ethnic areas. Villagers can also use their imagination to make cultural and creative products that they recognize. Compared with souvenirs, these items with strong marks of traditional villages in ethnic areas are in themselves a display of architectural cultural value, and they are also a continuation and re-creation of the cultural value of traditional villages in ethnic areas.

\subsection{Provide Certain Public Service Facilities for Laozhai}

On the basis of the protection of Laozhai, certain public service facilities are provided, with parking lots, garbage collection points and other municipal public service facilities, providing complete service facilities, providing convenient living conditions for residents who want to stay in Laozhai, and improving Occupancy rate. Implant public toilets in Laozhai, make reasonable planning, choose areas with more traffic nodes, set up public toilets, and assign special personnel to manage the toilets to improve the sanitary conditions in Laozhai in order to increase actual use efficiency.

\section{Conclusion}

This article studies the following issues: 1) the concept and classification of architectural culture and the architecture of the Qiang people; 2) an introduction to the architectural culture of Taoping Qiang Village; 3) the existence of cultural protection of Taoping Qiang Village coming up with some suggestions. Traditional village buildings should be protected, not only to protect the original architectural features and styles, but also to ensure that they are still playing their roles, so that they can truly reflect their cultural connotations and integrate with the surrounding cultural environment. This is an important way and guarantee for the protection of architectural culture. For Taoping Qiang Village, it is necessary to adhere to protection as the basis, give play to its cultural advantages, and realize the transformation of protection methods and make long-term planning. Only in this way can the culture of Qiangzhai be truly preserved. While studying the Taoping Qiang Village, we can also find out some problems and dilemmas about the architectural culture of the Qiang nationality, and use the experience gained from the research in the future protection and construction of other Qiang Villages and even the entire Qiang nationality culture. It has set a good example for the architectural culture of the Qiang nationality.

\section{Funding}

This paper is supported by the 2019 Graduate Innovative Scientific Research Project of Southwest University for Nationalities; project number: CX2019SZ05.

\section{Conflicts of Interest}

The author declares no conflicts of interest regarding the publication of this paper. 


\section{References}

[1] Ruan, Y. (2003) Protection and Inheritance of Chinese Traditional Architectural Culture. Century Architecture, No. Z1, 26-31.

[2] Ren, H. (2003) Qiang Nationality Architecture and Village. Architecture Journal, No. 8.

[3] Ji, F. (2000) Architecture of Qiang Nationality in China. Southwest Jiaotong University Press, Chengdu.

[4] Han, B. (2006) Lecture on Chinese Architecture Culture. Life-Reading·Xinzhi Sanlian Bookstore.

[5] Liu, Y. (2011) Landscape Analysis of the Qiang Traditional Settlement in the Minjiang River Basin: Taking Taoping Qiang Village as an Example. Chinese Art, No. 2, 177-177.

[6] Wang, W. (2013) A Preliminary Study on the Cultural Connotation of the Houses of the Qiang Nationality in Taoping. Beauty and Times (First Issue), No. 8, 61-63.

[7] Tang, Q. and Wang, S. (2013) The Embodiment of Multiculturalism in Qiang Architecture Decoration Art. Forum on Chinese Culture, No. 2, 149-154.

[8] Sun, J. and Li, X. (2008) An Interpretation of Architectural Aesthetics to Promote Vitality-Appreciation of Taoping Qiang Village. Civil Architecture and Environmental Engineering, 30, 12-16.

[9] Mao, Y. (2019) The Lost Roof of Taoping Qiang Village. Building Materials \& Decoration, No. 2, 137-138. 